Word count: 8730

\title{
THE IMPACT OF NEGATIVE MOOD ON TEAM PERFORMANCE
}

Received 28 March 2006

Accepted 25 June 2006

Peter J. Jordan

Griffith Business School

Department of Management

Griffith University

Brisbane QLD Australia.

Sandra A. Lawrence

Griffith Business School

Department of Management

Griffith University

Brisbane QLD, Australia.

Ashlea C. Troth

Griffith Business School

Department of Management

Griffith University

Brisbane QLD, Australia.

\begin{abstract}
Although organisations often implement team-based structures to improve performance, such restructuring does not automatically ameliorate poor performance. The study in this article explores the relationship between team members' negative mood and team processes (social cohesion, workload sharing, team conflict) to determine if negative mood has a detrimental effect on team performance via team processes. Two hundred and forty one participants completed surveys and were involved in an independently rated performance task that was completed over eight weeks. Negative mood was found to influence team processes and as a consequence, team performance. The results, however, were not uniformly negative. Implications for theory and practice are discussed.
\end{abstract}

Key Words: $\quad$ Mood; Team Performance; Conflict; Social Cohesion; Workload Sharing. 
Over the last couple of decades a significant number of organisations have restructured their operations around workgroups or teams to take advantage of the performance potential teams are able to produce (Beyerlein, Johnson \& Beyerlein 1997). Although there is general agreement that the introduction of teams contributes to improved performance (Wheelan 1999), teamwork does not automatically ameliorate poor performance. Several explanations have been given for negative team performance outcomes, including groupthink (e.g. Kerr \& Tindale 2004), member perceptions of social loafing (e.g. Mulvey \& Klein 1998) and poor goal setting (e.g. Wegge \& Kleinbeck 1996).

In a comprehensive review of the team effectiveness literature, Tannenbaum, Beard and Salas (1992) argue that team performance is not only predicated on organisational and situational contextual characteristics (e.g. organisational climate, reward systems) and effective team processes (e.g. coordination, communication, conflict resolution), but also on effective input characteristics (individual characteristics, work structure, team characteristics, task characteristics) and the interaction between these characteristics. They also argue that the various input characteristics all impact on team processes (see also Wheelan 1999). Indeed, researchers have identified, for example, that team performance is affected by such factors as organisational culture (Ashforth 1985), stages of team development (Gersick 1991; Tuckman 1965), length of tenure of the team (Pelled 1996), team diversity (Simons, Pelled \& Smith 1999; Swezey, Meltzer \& Salas 1994) and individual difference variables (Barrick, Stewart, Neubert \& Mount 1998; Stewart, Fulmer \& Barrick 2005).

Models of team performance, whether proposed by Tannenbaum et al. (1992), Gersick (1991) or Tuckman (1965), all essentially argue that high team performance results from the interaction between team members (i.e. the processes used within the team) and the 
working relationships established in the team. We argue that despite this extensive research, there is one area that has received less attention, the effect of the moods team members experience on team interactions and team performance.

In this paper, we explore the relationship between team member negative mood and team performance, and the role team processes play in mediating this relationship. While research has shown a broad range of team processes contribute to team performance, in this study we look at three team processes; the use of conflict in teams (Jehn, Northcraft \& Neale 1999), team social cohesion (Lieberman, Yalom \& Miles 1973), and workload sharing (Barrick et al. 1998) as significant contributors to team performance (Tannenbaum et al. 1992). In line with the broad argument developed by Yang and Mossholder (2004), we anticipate that the negative mood individuals bring into a team will influence the emotions experienced by these individuals during team interactions and how they contribute to team processes. This will have a subsequent negative impact on the overall performance of that team.

\section{Moods and Emotions in the Workplace}

At this stage it is important to distinguish between emotion, mood, and affect (Clore, LeDoux, Zajonc, Davidson \& Ekman 1994). Emotions are generally typified as short in duration, object-oriented and intense in their experience, while moods are generally experienced over a longer period with a lower level of intensity (Frijda 1986). In measuring emotions, Ortony, Clore and Collins (1988) observe that emotions can be measured by determining the intensity and valence of that experience. Moods, on the other hand, can be measured over much longer periods of time (Watson, Clark \& Tellegen 1988). Further, moods can be broadly categorized as either positive or negative in orientation (Watson et al. 1988). Affect is defined as expressed mood (Forgas 1995). Negative affectivity, in contrast to 
negative mood, can also be a personality trait that predisposes individuals towards a more reactive and negative response set.

To date, the majority of state-based emotions research has focussed on examinations of the role of emotions in organisations (e.g. Ashforth \& Humphrey 1995; Ashkanasy, Hartel \& Zerbe 2000; Fineman 2003; Weiss \& Cropanzano 1996), with emotions providing a significant explanation for individuals' behaviour. In an organisational setting, emotions determine affect-driven behaviours such as impulsive acts, organisational citizenship behaviours, and transient effort (Weiss \& Cropanzano 1996). Existing research into emotions in the workplace has focussed on individual level issues to show a positive relationship between emotional expression and organisational commitment (Allen \& Meyer 1990); a positive relationship between emotions and work motivation (George \& Brief 1996); and the variability of emotions that can be experienced at work (Rafaeli \& Sutton 1989).

In terms of mood states, Fisher (1997) argues that a link exists between mood and individual work performance. The relationship between individual mood and job-related attitudes such as job satisfaction, organisational commitment, emotional exhaustion, depersonalisation, personal accomplishment and turnover intentions also has been investigated (see meta-analysis Thoresen, Kaplan, Barsky, Warren \& De Chermont 2003). Thoresen et al., for instance, found negative mood to be negatively linked to perceptions of job satisfaction, organisational commitment and personal accomplishment, and positively linked to emotional exhaustion, depersonalisation and turnover intentions.

George and Zhou (2002) reported mixed results when they assessed the impact of mood on creativity. While positive mood led to better creative outcomes, it also produced complacency and reduced creativity. Negative mood also had mixed results. George and Zhou (2002) found that although negative mood generally had a negative relationship with creativity, negative mood did result in a more thorough consideration of alternatives. The 
advantages of negative mood are also reported by Wong, Yik and Kwong (2006). They found negative mood contributed to lower escalation of commitment in decisions. Individuals with negative mood were less likely to want to continue the unpleasant feelings associated with bad decisions and were quicker to withdraw from those situations.

Similar to the work on emotions, research on the impact of mood at work has focussed on individuals. An area largely ignored has been the impact moods have on team performance. There is, however, research looking at the impact of negative mood on relationships, an important element of teamwork. Research reveals that negative mood adversely effects relationships (Berkowitz 1990), and we believe it follows that negative mood within a team will also impact negatively on team performance. The study presented below investigates the influence negative mood has on team performance, and how specific team processes might mediate the proposed mood-performance link.

\section{Emotions, Mood and Team Performance}

Weiss and Cropanzano (1996) argue that the episodic and situationally specific nature of emotions in teams can both engender and decrease performance in business settings. For instance, emotions such as enthusiasm in a team problem-solving situation can provide positive energy that will invigorate others and lead to greater creativity (Barsade 2002; Kelly \& Barsade 2001). On the other hand, when linked to dysfunctional conflict, emotions can result in team members being distracted from their current work to focus on their feelings about the conflict (Jordan \& Troth 2002). Jordan, Ashkanasy and Hartel (2002) argue that individuals working in teams who have high emotional self-awareness or high emotional management skills are able to work more effectively together. This infers that teamwork involves a level of emotionality that can be used to maximize performance. If short-term emotions influence performance, then it follows that longer-term moods will also have an 
effect on team behaviour and team performance. It is reasonable to consider, therefore, how the prevailing mood of team members effects team performance.

Clearly, there is a body of research emerging around emotions and emotional reactions in teams. There is, however, less empirical evidence of the impact of mood on team performance. There is some evidence regarding the effect of mood on behaviour of team members’ that, in turn, may impact on team performance. For instance, George (1990) reported that teams high in negative mood engaged in less pro-social behaviour. Barrick et al. (1998: 382) argue that -

...teams with a greater tendency toward anxiety or negative affectivity are likely to be less capable of continued positive interactions. However, inclusion of a single team member who is emotionally unstable may also create a negative affect tone that makes it difficult for the team to work together.

In the next section, we develop a link between negative mood, emotions in teams and team processes as one possible explanation for poor performance in work teams.

\section{HYPOTHESES}

\section{Linking Negative Mood to Team Processes and Team Performance}

In this paper, we argue that to manage team processes effectively and improve team performance, team members need to be aware of, and ameliorate, negative moods. Barsade (2002) demonstrated that emotions are contagious in teams. We extend this argument and contend that team interactions can be affected by the prevailing mood of the members of that team. In other words, a team member's mood can influence the synergy between team members. If positive mood can increase people's ability to share and be creative (Isen \& Baron 1991), then it is probable that persistent negative mood can result in a deterioration of interactions between team members. If team members are not aware of, or fail to control, 
pervasive negative mood, then team processes and team performance can be negatively affected. Consequently, in this study we examine the impact of negative mood on team processes and team performance. In other words, our basic research question is to determine if negative moods have a negative impact on team performance by negatively influencing team processes.

As noted in the introduction, there are many factors that impact on team performance. In this study, we look at three specific team processes that the research evidence reveals have a significant impact on team performance: team social cohesion (Lieberman et al. 1973; Stewart et al. 2005); team workload sharing (Barrick et al. 1998); and the use of conflict in teams (Jehn et al. 1999). We should point out here that in developing our hypotheses we consider negative mood to have a long-term effect that persists within a group (see Clore et al. 1994; Frijda 1986). Effective teams expect the members of their teams to experience emotional fluctuations. Everyone gets in good moods and everyone gets in bad moods. The issue is not the existence of negative mood, but rather, how pervasive it is and if the constant experience of unresolved negativity impacts factors that otherwise would contribute to the performance of a team.

\section{Team social cohesion}

Team social cohesion has been shown to positively and strongly influence team performance generally (Lieberman et al. 1973), supervisor-ratings of team effectiveness and team viability (Barrick et al. 1998), and team behavioural performance and team efficiency (see meta-analysis Beal et al. 2003). Lieberman et al. (1973) define team social cohesion as team members' feelings of belongingness or attraction to the group. Barrick and his colleagues (1998) argue that social cohesion reflects synergistic interactions between team members, including the extent to which team members use positive communication techniques and operationalise more effective conflict resolution strategies. It is these interactions that result in closer positive working relationships. 
If a team member comes into the group in a negative mood, it is more likely that other team members will use the social closeness engendered by social cohesion to notice this mood and either point it out to their team member or make some moves to ameliorate that mood. In other words, team members who are close will try to ‘cheer each other up’ (Porter, Hollenbeck, Ilgen, Ellis, West \& Moon 2003). If team members are unable to influence this mood through direct or indirect means then the continuing presence of negative mood may have an impact on the social cohesion of the team. Teams rely on synergy for team performance (West 1994) and effective synergy is closely associated with higher levels of social cohesion experienced by team members (Barrick et al. 1998). However, those affected by negative mood perceive their teams to be less cohesive. Indeed, Aydin (2001) found that negative affectivity was negatively related to cohesion. Additionally, individuals in a negative mood are more likely to have doubts about trusting others and can withdraw their co-operation (Jones \& George 1998). Therefore, if one team member has a persistent negative mood, then interactions involving these negative individuals will be less effective, less synergistic, less cohesive. This then can lead to less synergistic team interactions and reduced levels of team social cohesion, which will negatively influence team performance. Based on this we predict that:

Hypothesis 1: Individual negative mood will have a negative influence on team performance by reducing those individual team member's perceptions of team social cohesion.

\section{Team workload sharing}

Team workload sharing is defined as the degree to which team members equitably share a project’s workload (Albanese \& Van Fleet 1985). Harkins (1987) argues that workload sharing enhances group effectiveness by preventing social loafing or free-riding. 
Team workload sharing positively influences objective ratings by supervisors and managers of team productivity (Campion, Medsker \& Higgs 1993) and supervisor-ratings of team effectiveness and team viability (Barrick et al. 1998).

Individuals in a negative mood generally have negative attributions towards others (Berkowitz 1990) and are likely to attribute any team problems to the failings of others (Alicke 2000). Examining the impact of mood on causal attributions, Forgas and Locke (2005) found a link between negative mood and causal explanations of work events. In other words, individuals in a negative mood were more likely to negatively perceive conditions in the workplace. Conversely, individuals in a positive mood generally make more positive and lenient judgements of others (Forgas, Bower \& Krantz 1984) and perform increased levels of helping behaviours (Salovey, Mayer \& Rosenhan 1991). Therefore, it is expected that a persistent negative mood will result in fewer helping behaviours and a negative attribution of the extent that others in the team contribute to outcomes. Based on this, we expect that individuals with high negative mood will perceive that their team members are not pulling their weight when it comes to workload sharing (Berkowitz, Hatfield \& Adams 1976). This will result in the individual constraining their contributions to the group as a result of them perceiving that others are not contributing (Carrell \& Dittrich 1978). Consequently, we expect that:

Hypothesis 2: Individual negative mood will have a negative influence on team performance by reducing those individual team members' perceptions of team workload sharing.

\section{Conflict}

Finally, one element that is often examined as a part of team performance is conflict (Mossholder, Settoon, Armenakis \& Harris 2000). Researchers have typically categorized conflict in teams into task, relationship (affective), and process conflict (Jehn 1995). Task conflict focuses on conflict over work content or tasks and is typically resolved using 
'rational' argument (Jehn 1995). Relationship (affective) conflict, on the other hand, refers to an emotional disagreement between individuals that generates strong negative emotions such as anger or hostility. Process conflict refers to disagreements over the team's approach to the task, its methods, and its group processes. Research regarding the impact of conflict has produced contradictory findings. For instance, Jehn (1995) found that although interpersonal conflict within a group often leads to lower group performance, task conflict within a group can lead to higher group performance. De Dreu \& Weingart (2003), alternatively, reported in a meta-analysis that the average correlation between performance and relationship conflict ( $\rho$ $=-.22)$ and task conflict $(\rho=-.23)$ was negative and significant.

Relationship conflict is consistently differentiated from task conflict and process conflict (e.g. Pelled, Eisenhardt \& Xin 1999), with task and process conflict seen as lacking emotion. Jordan and Troth (2002, 2004), however, argue that all team conflict is inherently emotional because it involves the perception of threats to individual or group goals. Threats generally give rise to negative emotions such as frustration, jealousy, anxiety and despair (Fredrickson 2003). As suggested earlier, these negative emotions can be strengthened by the prevailing mood of team members (Barsade 2002). The findings of De Dreu and Weingart (2003) and Jordan and Troth (2004) are supported by Yang and Mossholder (2004) who argue that the beneficial nature of task conflict is influenced by the extent to which negative emotionality is constrained in the group.

In examining the impact of negative mood on conflict, we consider that there are clear patterns that could emerge as a result of an individual's continuing negative mood. Research reveals that individuals in a negative mood are less tolerant of others (Berkowitz 1990). In examining conflict resolution, Schellenberg (1996) argues that the type of conflict resolution strategy that individuals choose will be influenced by the approach of other parties. In particular, a way of countering negative tactics is to confront them or compete with those individuals. Competition, however, can have an impact on relationships as competition 
results in a win lose outcome, an outcome that can result in increasing resentment (Schellenberg 1996). If this is the case, then individuals who have persistent negative moods are more likely to draw on a win / lose strategy and either compete or withdraw or avoid or accommodate in conflicts depending on their emotional attachment to the goals (Borisoff \& Victor 1998). As a consequence, it is likely that individuals in a persistent negative mood will create more interpersonal conflict within the team and will perceive an increase in their experience of interpersonal conflict (Aquino, Grover, Bradfield \& Allen 1999). Given that increased team interpersonal conflict leads to reduced team performance (De Dreu \& Weingart 2003), we expect that:

Hypothesis 3: Individual negative mood will have a negative influence on team performance through increasing those individual team members' perceptions of team interpersonal conflict.

Yang and Mossholder (2004) contend that the beneficial nature of task conflict is influenced by the extent to which negative emotionality is constrained in the group. While Yang and Mossholder's (2004) research focuses on emotions, we consider that this argument can be extended to encompass mood as well as emotion. We argue that individuals who have persistent negative moods are more likely to perceive task conflicts as unresolved and therefore will seek to continue, rather than resolve team task conflict. Research in relation to mood congruency reveals that while experiencing negative mood, people's perceptions and judgments are directed toward greater negativity (Mayer, Gaschke, Braverman \& Evans 1992). In other words, those who are experiencing persistent negative moods are less satisfied with decisions and less likely to see task conflict as being resolved. In the face of experiencing pervasive negative mood, affected individual team members would find it difficult to constrain their negative emotionality and therefore perceive higher levels of task conflict. As a consequence, it is likely that individuals in a persistent negative mood will create continuing task conflict within the team as a result of their more negative mindset 
(Aquino et al. 1999). This would result in the team experiencing higher levels of task conflict with a subsequent negative impact on team performance. If this is so then:

Hypothesis 4: Individual negative mood will have a negative influence on team performance through increasing those individual team members' perceptions of team task conflict.

Finally, in terms of team process conflict, we expect that individuals with persistent negative moods will increase process conflict to the detriment of the team. As noted earlier, we expect that an individual's negative mood will have a negative influence on their perceptions of workload sharing and team social cohesion, and increase their perceptions of team interpersonal conflict and task conflict. In the light of this, we expect that individuals with high negative mood to also require a thorough investigation of team processes. While this can have a positive effect on performance (Jehn \& Mannix 2001), there is a potential downside to constant monitoring. Combined with negative mood, constant monitoring can be inferred by team members as negative criticism and this can actually diminish performance. For instance, Baron (1988) found that the positive influence of intra-group conflict was completely eliminated by dysfunctional reactions of team members when negative criticisms were present. In the case of an individual in a negative mood, they may wish to challenge team processes more than is required due to their perceptions that workloads are not being shared equitably. Consequently:

Hypothesis 5: Individual negative mood will have a negative influence on team performance through increasing those individual team members' perceptions of team process conflict. 


\section{METHOD}

\section{Sample}

The participants in this study were 241 undergraduate university students enrolled in an introductory business course. A total of 231 respondents belonging to 57 groups completed useable surveys, an overall response rate of $96 \%$. The average size of the team was 4.4 members. Of the respondents, 119 (52\%) were male and 112 (48\%) were female; 100 (43\%) were born in Australia and 131 (57\%) were born overseas. The mean age of respondents was 21 years, ranging from 17 to 45 years.

\section{Procedure}

Participants were required to develop a team workshop presentation as a part of their coursework. This presentation was assessed by teaching staff. Teams were asked to develop a presentation around one of 5 topics: assertive behaviour, critical thinking, groupthink in teams, acculturation, and conflict in teams. At the start of the semester, students were assigned to work groups consisting of approximately 4 members. Students were allowed a choice as to which team to join. Teams met every week in class as well as outside of class to work on their projects for approximately 8 weeks.

A survey was distributed to students directly after the team presentation was completed asking the team members to reflect on the teamwork they had completed. The survey was completed anonymously by the students with both a unique identifier and a team identifier on each form to distinguish between the teams. Participation in this data collection was voluntary and those who wished to participate gave their surveys to the teaching staff and were subsequently given feedback on the survey including their individual responses compared to the overall class mean.

While the survey was completed in a single session, we took steps to overcome common method variance. In addition to asking respondents to report perceptions of team processes and self-rating their mood, the respondents were asked to complete both assessment of their peers and self-assessment of communication effectiveness and appropriateness during team interactions. Although this information was collected at the same 
time as this study, the communications rating data was related to another research project. Additionally, throughout the survey, respondents were encouraged to reflect upon their experiences and behaviours during the team interactions they had over the past two months, rather than simple personal preferences.

The student teams’ workshop performance scores were obtained from the teaching staff after all the presentations had been conducted and a moderation meeting completed. Performance scores were moderated through a meeting prior to assessing the teams to ensure that teaching staff were grading to a common standard and after assessment to ensure similar standards were applied. Four teaching staff with a minimum of 2 years teaching experience were responsible for assessing the workshop presentation assessment pieces of 57 student work teams. Teams’ workshop performance scores and survey responses were matched via an anonymous team identifier code given to student groups and the teaching staff at the beginning of the semester.

\section{Measures}

\section{Dependent variable}

Team performance was measured by four experienced teaching staff who assessed a group presentation. The teaching staff assessed group presentations out of a total of 10 marks, using the following criteria. Up to five marks were allocated to presentation delivery (appropriate communication by the team, audience engagement, group coordination) and up to five marks were allocated to presentation argument (expression of ideas supported in the literature and the effectiveness of the argument the team developed). The team performance scores were moderated to ensure similar standards were maintained in grading across groups before the final grades were distributed to the students. Moderation consisted of the establishment of common criteria for grading through discussion. Examination of the final means and distribution of grades for each of the teaching staff indicates that the marks were comparably assigned across groups. The size of the sample does not allow us to analyse these 
data using hierarchical linear modelling and therefore in this study we have assigned a team performance score to individual team members on the basis that each member of that team has contributed to the overall team performance. Indeed, Rousseau (1985) and Kozlowski and Klein (2000) suggests that cross level research examining the impact individuals have on group outcomes provides valuable information.

\section{Independent variable}

Negative mood was measured using ten items (e.g. 'Irritable') from Watson, Clark and Tellegen’s (1988) PANAS Scale. Respondents were asked to rate how they were feeling right now with regards to a number of mood states $(1=$ 'not at all' to $5=$ 'extremely'). We considered whether to use a measure that examined mood over the last two months, but decided on balance, to ask respondents to nominate current mood. Given mood is a slow changing and of moderate intensity (Frijda 1986), we consider that asking current mood provides a conservative measure of mood. Research from the initial validation study of the PANAS by Watson et al. (1988), show that there is no significant difference between asking for current mood and mood over the last few weeks. Moreover, they found no significant difference in responses to current mood instructions, collected two months apart. Watson et al. (1988) note that these results confirm previous evidence of momentary moods being a reflection of general affective levels (see Watson \& Clark 1984). Similarly, Fredrickson (2003) in a review of studies on individuals' memory of moods showed that only two experiences predicted responses, peak affect intensity and the final mood experienced. Finally, Meyer and Shack (1989) demonstrate that state affectivity (negative mood) is highly correlated with more pervasive measures of negativity $(r=0.98)$.

\section{Mediator variables}

Team social cohesion was assessed with 6 items (e.g. 'Team members consistently helped each other with the assessment task.') adapted from Stokes (1983) and O’Reilly, 
Caldwell, and Barnett (1989). Respondents were asked to rate their agreement about how well their team functioned as a group ( $1=$ 'strongly disagree' to $5=$ 'strongly agree').

Team workload sharing was assessed with 3 items (e.g. 'Everyone on my team did their fair share of the work.') from Campion et al. (1993). Respondents were asked to rate their agreement about how well their team shared the workload in relation to the presentation assessment task ( 1 = 'strongly disagree' to 5 = 'strongly agree').

Team interpersonal conflict, task conflict and process conflict was assessed with 10 items from Jehn (1995; Shah \& Jehn 1993). Respondents were asked to rate how much conflict their presentation team experienced through out the semester $(1=$ 'none' to $5=$ 'all the time'). Four items assessed interpersonal conflict (e.g. 'How much friction was there in your group?'). Three items assessed task conflict (e.g. 'How frequently were there conflicts about ideas in your group?'). Three items assessed process conflict (e.g. 'How often did your group members disagree about who should do what?’). All independent and mediator variables were obtained from validated measures that had demonstrated adequate internal consistency statistics.

\section{RESULTS}

Data screening for respondent errors and omissions was conducted prior to analysis. Cases were deleted if more than half the items were missing from a particular scale. As the remaining missing data for any particular scale item was $2 \%$ or less, it was deemed to be missing at random (Cohen \& Cohen 1983). The missing data was therefore replaced by values estimated by the Expectation-Maximization (EM) imputation method in SPSS 10.0.5. Variables were formed from averaged composites of the scale items. Table 1 presents the means, standard deviations, inter-item reliabilities and bi-variate correlations between the variables. Although small amounts of skewness and kurtosis were present in some of the variables analyzed, no obvious non-normality, curvilinearity or homoscedasticity of residuals were evident in the regression findings and thus the results can be deemed robust. 
Insert Table 1 about here

Hypotheses were tested with path analysis via a series of hierarchical regressions, where the dependent variable was team performance, the independent variable was negative mood, and the mediating variables were team social cohesion, team workload sharing, team interpersonal conflict, team task conflict and team process conflict. The independent variable was considered in the first step and the mediators were entered in the second step. Results of the hypothesis tests are presented in Table 2.

Insert Table 2 about here

Hypothesis 1 and 2 predicted the negative mediated relationship of team members' negative mood on team performance, through decreased perceptions of team social cohesion and team workload sharing. Support was found for Hypothesis 1 (Models 1, 6, 7, 8), but not for Hypothesis 2 (Models 2, 6, 7, 8). Satisfying Baron and Kenny's (1986) conditions for a mediated model, negative mood was a significant predictor when both team social cohesion $(\beta=-.26, p<.001$; Model 1$)$ and team workload sharing $(\beta=-.28, p<.001$; Model 2) were dependent variables. Only team social cohesion significantly predicted team performance ( $\beta$ $=.24, p<.01$; Model 7; $\beta=.22, p<.01$; Model 8). Negative mood was also a significant predictor of team performance ( $\beta=-.28, p<.001$; Model 6$)$. The beta weight for negative mood in Model 6 was reduced but still significant in the full model $(\beta=-.19, p<.001$; Model 
8) when the mediators were introduced. Thus, the negative mood - team performance relationship was partially mediated. The significance of this partial mediation effect was confirmed with a follow-up Sobel test conducted using the web-based statistical tool of Preacher and Leonardelli (2006; Sobel: $z=-2.49, p<.01$, Aroian: $z=-2.44, p<.01$ ). Therefore, negative mood had a net negative, partial indirect effect on team performance by decreasing team members’ perceptions of team social cohesion.

Hypothesis 3, 4 and 5 predicted a negative mediated relationship of team members’ negative mood on team performance, through increased perceptions of team interpersonal conflict, team task conflict and team process conflict, respectively. No support was found for Hypothesis 3 (Models 3, 6, 7, 8), however, negative mood was found to be a significant predictor of team interpersonal conflict ( $\beta=.27, p<.001$; Model 3). Support was found for Hypothesis 5 (Models 5, 6, 7, 8). The mediated relationship detected in relation to Hypothesis 4 (Models 4, 6, 7, 8) was not in the predicted direction. Rather, we found a net positive mediated relationship for the effect of negative mood on team performance via team task conflict. Satisfying Baron and Kenny’s (1986) conditions for a mediated model, negative mood was a significant predictor when team task conflict $(\beta=.17, p<.05$; Model 4$)$ and team process conflict $(\beta=.22, p<.001$; Model 5) were dependent variables. Both team task conflict $(\beta=.22, p<.01$; Model 7; $\beta=.22, p<.01$; Model 8$)$ and team process conflict $(\beta=$ $.26, p<.01$; Model 7; $\beta=-.24, p<.01$; Model 8) significantly predicted team performance. Negative mood was also a significant predictor of team performance $(\beta=-.28, p<.001$; Model 6). The beta weight for negative mood in Model 6, although reduced, was still significant in the full model ( $\beta=-.19, p<.001$; Model 8) when the mediators were introduced. Thus, the negative mood - team performance relationship was partially mediated in both cases. Follow-up Sobel tests confirmed the significance of the partial mediation effects involving task conflict (Sobel: $z=-2.42, p<.05$, Aroian: $z=-2.38, p<.05$ ) and 
process conflict (Sobel: $z=2.46, p<.01$, Aroian: $z=2.42, p<.05$ ). Therefore, negative mood had a net positive, partial indirect effect on team performance by increasing team members’ perceptions of team task conflict. On the other hand, negative mood had a net negative partial indirect effect on team performance by increasing team members’ perceptions of team process conflict.

\section{DISCUSSION}

In this study we examined the relationship between negative mood, team cohesion, workload sharing, team conflict and team performance. Significantly, an independent measure of team performance was collected using four independent raters, who participated in two stages of moderation to ensure consistency in performance scoring. Participants were asked to complete the survey reflecting on their experiences in their teams immediately after the performance task had been completed. It could be argued that following the completion of a performance task that involved two months of preparation, that general emotional milieu and consequently the individual's mood may have been more euphoric or more positive than normal due to the relief that is associated with a task completion. Indeed, Mitchell, Thompson, Peterson, and Cronk (1997) found that individuals suffer from a Rosy View effect where following a stressful or negative event, individuals can remember the experience fondly. We collected the survey data immediately after such an event. Despite the potential for a Rosy View phenomenon occurring in the self-report data collected, it is important to note that negative mood was found to influence both perceptions of team process variables and the independently rated performance data. Thus, we argue that the results can be considered a conservative reflection of the influence of negative mood during student team interactions. 
In this study, we found that negative mood had a negative effect on performance through its impact on process conflict (Hypothesis 5), and a positive effect on performance through its impact on task conflict. This second finding was in the opposite direction of our prediction (Hypothesis 4). In relation to Hypothesis 1, we expected to find that negative mood would have a negative impact on performance mediated by team cohesion. In support of this, there was a net negative effect of negative mood on performance via decreasing perceptions of cohesion.

A significant finding was that negative mood has a direct negative impact on objectively rated performance. All three mediation effects were only partial, so the negative mood - performance link is an important finding of this study. This finding reinforces the idea that negative mood not only influences perceptions of team processes for those affected by negative mood, but provides indirect evidence that those negative individuals are behaviourally influencing team processes in a way that has an important impact on overall team performance.

The finding that negative mood positively indirectly influenced task performance by increasing perceptions of task conflict (counter finding for Hypothesis 4) is confronting. This finding suggests that the argument developed by Yang and Mossholder (2004) about the impact of negative mood on team performance is more complex than first proposed. Yang and Mossholder (2004) argue that the beneficial nature of task conflict is influenced by the extent to which negative emotionality is constrained in the group. Our findings suggest that increasing negative mood in the team can improve task performance. Previous research in this area has produced mixed results for the relationship between task conflict and team performance (see DeDreu \& Weingart 2003; Jehn 1995). We see our finding as significant and consider that the inclusion of negative mood in this study may go some way to explain the inconsistent results found in previous research. Negative mood is linked to pessimism 
(Robinson-Whelen, Kim, MacCallum \& Kiecolt-Glaser 1997) and one constant finding is the link between pessimism and accurate assessment of situations (Waller 2003). It is likely that individuals who experience a negative mood could more accurately assess problems in analysing tasks. Based on this argument, individuals in a negative mood could become the squeaky wheel in a team that identifies task problems and prevents the team from undergoing groupthink, thereby improving task performance.

This alternative explanation for our finding suggests the need to redefine Yang and Mossholder's (2004) argument. At present, Yang and Mossholder suggest that emotional constraint occurs on a continuum where greater emotional constraint leads to better task performance. Our finding suggests that rather than a simple linear relationship between the expression of emotionality and task performance, there may be an inverted U relationship. In other words, while too much emotionality can damage task performance, too little emotionality can also be detrimental as it reduces one’s motivation to achieve a good outcome. This suggests that there is a moderate level of emotionality that contributes to better team performance.

\section{Limitations and Future Directions}

It is important to acknowledge the limitations of our study. Primarily, our sample consisted of undergraduate students. The average age of the respondents was 21 years. To improve the ability to generalise our findings, we consider this study needs to be transferred to a work setting dealing with in situ teams. By moving our research into a business setting and working with existing work groups, our research could also be extended to consider the influence of negative mood on actual team performance. In such cases, problem solving decision-making processes can have significant organisational and financial consequences and this has the potential to raise the level of emotionality in the group (Barsade 2002). 
Within this context, we could also examine the impact of prior and ongoing relationships in managing negative mood in fellow team members within the survey.

Another limitation may have been common method variance. As noted in the procedure section, the combination of self-ratings, team ratings, peer ratings, and focusing students to reflect on past experiences may have ameliorated the effects of any common method variance affecting the relationship between negative mood and team process measures due to the consistency motif or method effects. We also noted earlier that the Rosy View effect (Mitchell et al. 1997) may have also had an influence on the relationship between the variables. This having been noted, an examination of the bi-variate correlations suggests that multicollinearity, which can be a reflection of the consistency motif, is an unlikely issue between the variables of interest.

Finally, now that we have established in this study that individual team member's mood affects team performance, future research can move on to examine the impact of team mood on team processes and performance outcomes. Additionally, by using Hierarchical Linear Modelling, this research could unlock the impact of individual contributions to team performance.

\section{Acknowledgements}

The research in this article was funded by a grant from the Australian Research Council.

\section{Conclusion}

In this article we explored the relationship between negative mood and team processes to unravel their effect on team performance. In particular, we examined the impact of negative mood on conflict in teams, team social cohesion, and team workload sharing. We expected to find that mood, and in this case negative mood, influences team processes and as 
a consequence, team performance. Our findings broadly support these predictions. The data, however, also show that negative mood does not consistently have a negative impact on team performance. The results suggest that negative mood can contribute to performance through increased task conflict. The implications of our study highlight the importance of managing mood in the workplace. Managers need to be aware of the importance of managing not only ambient mood produced in teams, but also the moods team members may bring with them to work.

\section{REFERENCES}

Albanese R and Van Fleet DD (1985) Rational behavior in groups: The free-riding tendency, Academy of Management Journal 10(2): 244-255.

Alicke MD (2000) Culpable control and the psychology of blame, Psychological Bulletin 126(4): 556-574.

Allen NJ and Meyer JP (1990) The measurement and antecedents of affective, continuance and normative commitment to the organization, Journal of Occupational Psychology 63: 1-18.

Aquino K, Grover S, Bradfield M and Allen D (1999) The effects of negative affectivity, hierarchical status, and self-determination on workplace victimization, Academy of Management Journal 42: 260-273.

Ashforth BE (1985) Climate formation: Issues and extensions, Academy of Management Review 10: 837-847.

Ashforth BE and Humphrey RH (1995) Emotion in the workplace: A reappraisal, Human Relations 48: 97-125.

Ashkanasy NM, Härtel CEJ, and Zerbe WJ (Eds) (2000) Emotions in the workplace: Research, theory, and practice, Quorum Books, Westport CT

Aydin B and Oztutuncu F (2001) Examination of adolescents' negative thoughts, depressive mood, and family environment, Adolescence 36(141): 77-83.

Baron, RA (1988) Negative effects of destructive criticism: impact on conflict, self-efficacy, and task performance, Journal of Applied Psychology 73: 199-207.

Baron RM and Kenny DA (1986) The moderator-mediator variable distinction in social psychological research: Conceptual, strategic and statistical considerations, Journal of Personality and Social Psychology 51: 1173-1182 
Barrick M, Stewart G, Neubert MJ and Mount M (1998) Relating member ability and personality to work-team processes and team effectiveness, Journal of Applied Psychology 83: 377-319.

Barsade SG (2002) The ripple effects: Emotional contagion and its influence on group behavior, Administrative Science Quarterly 47(4): 644-675.

Beal DJ, Cohen RR, Burke MJ and McLendon CL (2003) Cohesion and performance in groups: A meta-analytic clarification of construct relations, Journal of Applied Psychology 88(6): 989-1004.

Berkowitz L (1990) On the formation and regulation of anger and aggression. A cognitiveneoassociationistic analysis, American Psychologist 45(4): 494-503.

Berkowitz L, Hatfield EJ and Adams S (1976) Equity theory: Toward a general theory of social interaction, Academic Press, New York.

Beyerlein MM, Johnson DA and Beyerlein ST (Eds.) (1997) Advances in interdisciplinary studies of work teams, JAI Press, Greenwich NJ.

Borisoff D and Victor DA (1998) Conflict management: a communication skills approach, Allyn and Bacon, Boston MA.

Campion MA, Medsker GJ and Higgs AC (1993) Relations between work group characteristics and effectiveness: Implications for designing effective work groups, Personnel Psychology 46: 823-850.

Carrell, MR and Dittrich JE (1978) Equity theory: The recent literature, methodological considerations, and new directions, Academy of Management Review 3: 202-210.

Clore GL, LeDoux JE, Zajonc RB, Davidson RJ and Ekman P (1994) In Paul Ekman, and Richard J. Davidson (Eds.) The nature of emotion: Fundamental questions: 283-299. Oxford University Press, New York NY.

Cohen J and Cohen P (1983) Multiple regression/correlation for the behavioral sciences (third edition), Erlbaum, Mahwah NJ.

De Dreu C and Weingart L (2003) Task versus relationship conflict, team performance, and team member satisfaction, Journal of Applied Psychology 88(4): 741-749.

Druskat V U and Wolff SB (2001) Building the emotional intelligence of groups, Harvard Business Review March: 81-90.

Fineman S (2003) Understanding emotion at work, Sage, London.

Fisher CD (2000) Mood and emotions while working: Missing pieces of job satisfaction? Journal of Organizational Behavior. 21: 185-202.

Forgas JP (1995) Mood and judgment: The affect infusion model (AIM), Psychological Bulletin 117: 39-66. 
Forgas JP, Bower GH and Krantz S (1984) The influence of mood on perceptions of social interactions, Journal of Experimental Social Psychology 20: 497-513.

Forgas JP and Locke J (2005) Affective influences on causal inferences: The effects of mood on attributions for positive and negative interpersonal episodes, Cognition \& Emotion 19: 1071-1081.

Fredrickson BL (2000) Extracting meaning from past affective experiences: The importance of peaks, ends, and specific emotions, Cognition \& Emotion 14: 577-606.

Fredrickson BL (2003) The value of positive emotions, American Scientist 394: 330-335.

Frijda NH (1986) The emotions. Cambridge University Press, Cambridge.

George JM (1990) Personality, affect, and behavior in groups, Journal of Applied Psychology 75: $107-116$

George JM and Brief AP (1996) Motivational agendas in the workplace: The effects of feelings on focus of attention and work motivation, Research in Organizational Behavior 18: 75-109.

George JM and Zhou J (2002) Understanding when bad moods foster creativity and good ones don't: the role of context and clarity of feelings, Journal of Applied Psychology 87: 687-97.

Gersick CJ (1991) Revolutionary change theories: A multilevel exploration of the punctuated equilibrium paradigm, Academy of Management Review 16: 10-36.

Harkins S (1987) Social facilitation and social loafing, Journal of Experimental Social Psychology 23: 1-18.

Isen AM and Baron RA (1991) Positive affect as a factor in organizational behavior, Research in Organizational Behavior 13: 1-53.

Jehn K (1995) A multimethod examination of the benefits and determinants of intragroup conflict, Administrative Science Quarterly 40: 256-282.

Jehn K and Mannix E (2001) The dynamic nature of conflict: A longitudinal study of intragroup conflict and group performance, Academy of Management Journal 44(2): 238-251.

Jehn KA, Northcraft GB and Neale MA (1999) Why differences make a difference: A field study in diversity, conflict, and performance in workgroups, Administrative Science Quarterly 44: 741 -763

Jones GR and George JM (1998) The experience and evolution of trust: implications for cooperation and teamwork, Academy of Management Review 23: 531-546, 
Jordan P J, Ashkanasy NM, Hartel, CEJ and Hooper G (2002) Workgroup emotional intelligence: Scale development and relationship to team process effectiveness and goal focus, Human Resource Management Review 12: 195-214.

Jordan PJ and Troth AC (2002) Emotional intelligence and conflict resolution: Implications for human resource development, in Callahan JL and McCollum EE (Eds) Advances in Developing Human Resources, Special Edition on Perspectives of Emotion and Organizational Change 4(1): 62-79.

Jordan PJ and Troth AC (2004) Managing emotions during team problem solving: Emotional intelligence and conflict resolution, Human Performance 17 (2): 195-218.

Kelly JR and Barsade SG (2001) Mood and emotions in small groups and work teams, Organizational Behavior and Human Decision Processes 86(1): 99-130

Kerr NL and Tindale RS (2004) Small group decision making and performance, Annual Review of Psychology 55: 623-656.

Kozlowski SWJ and Klein KJ (2000) A levels approach to theory and research in organizations, in Klein KJ and S. W. J. Kozlowski (Eds) Multilevel theory, research and methods in organizations, pp 3-90, Jossey-Bass, San Francisco CA.

Lieberman MA, Yalom ID and Miles MB (1973) Encounter groups: First facts, New York, NY: Basic Books.

Mayer JD, Gaschke YN, Braverman DL and Evans TW (1992) Mood-congruent judgment is a general effect, Journal of Personality and Social Psychology 63: 119-132.

Mitchell TR, Thompson L, Peterson E and Cronk R (1997) Temporal adjustments in the evaluation of events: The 'rosy view', Journal of Experimental Social Psychology 33(4): 421-448.

Mossholder K, Setton R, Armenakis A and Harris S (2000) Emotion during organizational transformation: An interactive model of survivor reactions, Group and Organization Management 25(3): 220-243

Mulvey PW and Klein HJ (1998) The impact of perceived loafing and collective efficacy on group goal processes and group performance, Organizational Behavior and Human Decision Processes 74: 62-87.

O’Reilly C, Caldwell D and Barnett W (1989) Work group demography, social integration, and turnover, Administrative Science Quarterly 34: 21-37.

Ortony A, Clore GL, and Collins A (1988) The cognitive structure of emotions, New York, NY: Cambridge University Press.

Pelled LH (1996) Demographic diversity, conflict, and work group outcomes: An intervening process theory, Organization Science 7: 615-631. 
Pelled LH, Eisenhardt KM and Xin KR (1999) Exploring the black box: An analysis of work group diversity, conflict, and performance, Administrative Science Quarterly 44(1): 128.

Porter COLH, Hollenbeck JR, Ilgen DR, Ellis APJ, West BJ and Moon H (2003) Backing up behaviors in teams: The role of personality and legitimacy of need, Journal Of Applied Psychology 88: 391-403.

Preacher KJ and Leonardelli GJ (2006) Calculators for the Sobel test. Accessed at http://www.unc.edu/ preacher/sobel/sobel.htm on 28 April 2006.

Rafaeli A and Sutton RI (1989) The expression of emotion in organizational life, Research in Organizational Behavior 11: 1-42.

Robinson-Whelen S, Kim C, MacCallum RC and Kiecolt-Glaser JK (1997) Distinguishing optimism from pessimism in older adults: Is it more important to be optimistic or not to be pessimistic? Journal of Personality and Social Psychology 73(6): 1345-53.

Rousseau DM (1985) Issues of level in organizational research: Multi-level and cross-level perspectives. In L. L. Cummings and B. Staw (Eds.) Research in Organizational Behavior 7: 1-37.

Salovey P, Mayer JD and Rosenhan DL (1991) Mood and helping: Mood as a motivator of helping and helping as a regulator of mood. In M. S. Clark (Ed) Review of Personality and Social Psychology, 12: 215-237. New York, NY: Sage.

Schellenberg JA (1996) Conflict resolution: Theory, research, and practice, State University of New York Press, Albany NY.

Shah P and Jehn K (1993) Do friends perform better than acquaintances? The interaction of friendship, conflict and task, Group Decision and Negotiation 2: 149-166.

Simons T, Pelled LH and Smith KA (1999) Making use of difference: Diversity, debate, and decision comprehensiveness in top management teams, Academy of Management Journal 42: 662-673.

Stewart GL, Fulmer IS and Barrick MR (2005) An exploration of member roles as a multilevel linking mechanism for individual traits and team outcomes, Personnel Psychology 58: 343-365.

Stokes JP (1983) Toward an understanding of cohesion in personal change groups, International Journal of Group Psychotherapy 33(4): 449-67.

Swezey RW, Meltzer AL and Salas E (1994) Some issues involved in motivating teams, in O'Neil Jr.HF and Drillings M (Eds) Motivation: Theory and research, pp 141-169, Lawrence Erlbaum Associates, Hillsdale NJ.

Tannenbaum SI, Beard RL and Salas E (1992) Team building and its influence on team effectiveness: An examination of conceptual and empirical developments, in Kelley K 
(Ed.) Issues, theory, and research in industrial/organizational psychology, 82: 117-153, Elsevier Science, Amsterdam.

Thoresen CJ, Kaplan SA, Barsky AP, Warren CR, and de Chermont K (2003) The affective underpinnings of job perceptions and attitudes: a meta-analytic review and integration, Psychological Bulletin 129(6): 914-945.

Tuckman B (1965) Developing sequences in small groups, Psychological Bulletin 63: 384399.

Waller BN (2003) The sad truth: Optimism, pessimism, and pragmatism, Ratio 16(2): 189.

Watson D and Clark LA (1984) Negative affectivity: The disposition to experience aversive emotional states, Psychological Bulletin 96: 465-490.

Watson D, Clark LA and Tellegen A (1988) Development and validation of brief measures of positive and negative affect: The PANAS scales, Journal of Personality and Social Psychology 54: 1063-1070.

Wegge J and Kleinbeck U (1996) Goal setting and group performance: impact of achievement and affiliation motives, participation in goal setting, and task interdependence of group members, in Gjesme T \& Nygard R (Eds) Advances in Motivation, pp145-177, Scandinavian University Press, Oslo Norway.

Weiss H and Cropanzano R (1996) Affective events theory: A theoretical discussion of the structure, causes and consequences of affective experiences at work, Research in Organizational Behavior 18: 1-74.

West MA (1994) Effective teamwork, BPS Books, Leicester England.

Wheelan SA (1999) Creating effective teams: A guide for members and leaders, Sage, Thousand Oaks CA.

Yang JX and Mossholder KW (2004) Decoupling task and relationship conflict: The role of intra-group emotional processing, Journal of Organizational Behavior 25: 589-605. 
Table 1: Means, Standard Deviations, Correlations and Inter-Item Reliabilities ${ }^{\mathrm{a}}$

\begin{tabular}{|c|c|c|c|c|c|c|c|c|c|}
\hline Variables & Mean & SD & 1 & 2 & 3 & 4 & 5 & 6 & 7 \\
\hline \multicolumn{10}{|l|}{ Dependent Variables } \\
\hline 1. Team Performance & 7.68 & .79 & --- & & & & & & \\
\hline \multicolumn{10}{|l|}{ Independent Variables } \\
\hline 2. Negative Mood & 1.62 & .67 & $-.28 * * *$ & $(.89)^{\mathrm{b}}$ & & & & & \\
\hline \multicolumn{10}{|l|}{ Mediators } \\
\hline 3. Team Social Cohesion & 4.12 & .62 & $.32 * * *$ & $-.26 * * *$ & $(.85)$ & & & & \\
\hline 4. Team Workload Sharing & 3.94 & 1.02 & $.18 * *$ & $-.28 * * *$ & $.54 * * *$ & $(.88)$ & & & \\
\hline 5. Team Interpersonal Conflict & 1.89 & .79 & $-.25 * * *$ & $.27 * * *$ & $-.34 * * *$ & $-.26 * * *$ & $(.85)$ & & \\
\hline 6. Team Task Conflict & 2.25 & .85 & -.03 & $.17 * *$ & $-.14^{*}$ & -.12 & $.42 * * *$ & $(.83)$ & \\
\hline 7. Team Process Conflict & 1.88 & .82 & $-.26 * * *$ & $.22 * * *$ & $-.27 * * *$ & $-.18 * *$ & $.51 * * *$ & $.62 * * *$ & $(.80)$ \\
\hline
\end{tabular}
${ }^{\mathrm{a}} \mathrm{n}=231$

b Figures in parentheses indicate inter-item reliabilities. 
Table 2: Regression Results for Determinants of Group Process Perceptions and Team Performance ${ }^{\mathrm{a}}$

\begin{tabular}{|c|c|c|c|c|c|c|c|c|}
\hline \multirow{2}{*}{ Dependent Variable } & \multirow{2}{*}{$\begin{array}{c}\text { Team } \\
\text { Cohesion } \\
\text { Model } 1\end{array}$} & \multirow{2}{*}{\begin{tabular}{|c|} 
Team \\
Workload \\
Sharing \\
Model 2 \\
\end{tabular}} & \multirow{2}{*}{\begin{tabular}{|c|} 
Team \\
Interpersonal \\
Conflict
\end{tabular}} & \multirow{2}{*}{$\begin{array}{l}\text { Team } \\
\text { Task } \\
\text { Conflict } \\
\text { Model 4 }\end{array}$} & \multirow{2}{*}{$\begin{array}{c}\text { Team } \\
\text { Process } \\
\text { Conflict } \\
\text { Model } 5\end{array}$} & \multicolumn{3}{|c|}{ Team Performance } \\
\hline & & & & & & Model 6 & Model 7 & Model 8 \\
\hline $\begin{array}{l}\text { Independent Variable } \\
\text { Negative Mood } \\
\text { Mediators } \\
\text { Team Social Cohesion } \\
\text { Team Workload Sharing } \\
\text { Team Interpersonal Conflict } \\
\text { Team Task Conflict } \\
\text { Team Process Conflict }\end{array}$ & $-.26 * * *$ & $-.28 * * *$ & $.27 * * *$ & $.17^{*}$ & $.22 * * *$ & $-.28 * * *$ & $\begin{array}{l}.24^{* *} \\
-.01 \\
-.14^{+} \\
.22^{* *} \\
-.26^{* *}\end{array}$ & $\begin{array}{l}-.19 * * \\
.22 * * \\
-.04 \\
-.11 \\
.22 * * \\
-.24 * *\end{array}$ \\
\hline $\begin{array}{l}\mathbf{R}^{2} \\
\text { Total Adjusted } \mathbf{R}^{2} \\
\text { Independent Variables } \\
\text { Adjusted } \mathbf{R}^{2} \\
\text { Mediator Variables } \\
\text { Incremental Adjusted } \mathbf{R}^{2}\end{array}$ & $\begin{array}{l}.07^{* * *} \\
.06 \\
.06^{* * *}\end{array}$ & $\begin{array}{l}.08^{* * *} \\
.08 \\
.08^{* * *}\end{array}$ & $\begin{array}{l}.07 * * * \\
.07 \\
.07 * * *\end{array}$ & $\begin{array}{l}.03^{* *} \\
.02 \\
.02^{* *}\end{array}$ & $\begin{array}{l}.05^{* * *} \\
.04 \\
.04^{* * *}\end{array}$ & $\begin{array}{l}.08^{* * *} \\
.08 \\
.08^{* *}\end{array}$ & $\begin{array}{l}.17^{* * * *} \\
.15^{1} \\
.15^{* * *}\end{array}$ & $\begin{array}{l}.20^{* * *} \\
.18\end{array}$ \\
\hline
\end{tabular}

